\title{
Population ecology of Muggiaea atlantica (Cnidaria, Siphonophora) in the Western English Channel
}

\author{
Michael Blackett ${ }^{1,3, *}$, Cathy H. Lucas ${ }^{1}$, Rachel A. Harmer ${ }^{2}$, Priscilla Licandro ${ }^{3}$ \\ ${ }^{1}$ Ocean and Earth Science, National Oceanography Centre, University of Southampton Waterfront Campus, European Way, \\ Southampton, SO14 3ZH, UK \\ ${ }^{2}$ Plymouth Marine Laboratory, Prospect Place, The Hoe, Plymouth, PL1 3DH, UK \\ ${ }^{3}$ Sir Alister Hardy Foundation for Ocean Science, The Laboratory, Citadel Hill, Plymouth, PL1 2PB, UK
}

\begin{abstract}
Recent observations suggest that the siphonophore Muggiaea atlantica is expanding its geographical distribution. The mechanisms behind this expansion remain unclear due to our limited knowledge of the species' ecology. We modelled the functional relationship between the 2 main life-cycle stages of $M$. atlantica over a 5 yr period (2009-2013) in the Western English Channel. Our aims were to determine the key features of the species' population dynamics and the influence of local environmental conditions on its population development. Our results highlighted a strong coupling between the timing of specific environmental conditions and the development of the M. atlantica population, thereby explaining interannual differences in the phenology of its blooms. Population development commenced with the initiation of eudoxid production by the overwintering polygastric stages. This reproductive event was linked to the onset of a spring temperature threshold, suggesting a critical basal limit of $10^{\circ} \mathrm{C}$ for eudoxid production. Interannual variability in the timing of this threshold modulated the degree of mismatch between the developing $M$. atlantica population and the availability of copepod prey. Unusually cold conditions in the spring of 2010 and 2013 limited the capacity for M. atlantica to initiate eudoxid production leading to poor trophic phasing and the production of single autumn cohorts. In contrast, warmer conditions during spring 2009, 2011, and 2012 facilitated earlier population development, optimal trophic phasing and the production of both summer and autumn cohorts. These findings represent an important addition to our understanding of the ecology of $M$. atlantica in the Northeast Atlantic.
\end{abstract}

KEY WORDS: Muggiaea atlantica - Jellyfish - Population dynamics · Population ecology · Phenology $\cdot$ Phenological shift $\cdot$ Trophic mismatch

\section{INTRODUCTION}

Cnidarian jellyfish (medusae and siphonophores) are a ubiquitous component of the pelagic ecosystem. These animals play a key ecological role as predators and competitors that can modulate the structure and dynamics of marine communities (Mills 1995, Pitt et al. 2009). Most cnidarian jellyfish have

\footnotetext{
*Corresponding author: mb10g11@noc.soton.ac.uk
}

opportunistic life history traits (high reproductive potential and high feeding rates) that enable rapid population increase in response to favourable environmental conditions (Lucas \& Dawson 2014). The seasonal abundance of these species fluctuates dramatically, with dense accumulation separated by periods of absence or rarity (Lucas \& Dawson 2014). Consequently, their structuring effect on the pelagic

(C) The authors 2015. Open Access under Creative Commons by Attribution Licence. Use, distribution and reproduction are unrestricted. Authors and original publication must be credited. 
community is complex and dynamic (e.g. Matsakis \& Conover 1991). Knowledge of the mechanisms that regulate gelatinous predator populations is fundamental to our understanding of the functioning of marine ecosystems (Condon et al. 2013).

The population dynamics of cnidarian jellyfish are the result of life cycle and life history adjustments (sensu Boero et al. 2008), modulated by myriad environmental factors. Most cnidarian jellyfish have complex, metagenic life cycles alternating between sexual and asexual generations. Meroplanktonic species typically employ life cycle adjustments (qualitative changes at the individual level) and may persist locally as sexual pelagic or asexual benthic life stages at different times (Boero et al. 2008). In contrast, holoplanktonic species tend to adopt life history adjustments (quantitative changes at the population level) and may undergo alternating periods of high and low absolute abundance (Boero et al. 2008). Improving our knowledge of the inter-relationships between different cnidarian jellyfish life-cycle stages and the influence of environmental factors would enable a better understanding of their population dynamics (Lucas 2001, Lucas \& Dawson 2014).

Calycophoran siphonophores are holoplanktonic colonial cnidarian jellyfish (Mackie et al. 1987). These typically small and active species are ambush predators that release a network of tentacles to entrap zooplankton prey (Mackie \& Boag 1963). The life cycle of the Calycophora is characterised by an alternation between an asexual polygastric stage and a sexual eudoxid stage. Polygastric colonies asexually produce a chain of cormidia (each cormidium comprising single nutritive, reproductive and buoyant zooids) along a central stem. As the chain grows successive cormidia are released as autonomous sexual eudoxid colonies. The eudoxid stage buds successive reproductive gonophores that, via external fertilisation, recruit new polygastric colonies through 2 short-lived larval stages, the planula and calyconula (Carré \& Carré 1991). Simultaneous asexual and sexual reproduction, high fecundity, rapid growth rates and short generation times enable the rapid development of large multivoltine blooms (Mackie et al. 1987).

In temperate biomes of the 3 great oceans the calycophoran siphonophore Muggiaea atlantica represents a major component of neritic gelatinous zooplankton (Mapstone 2009, 2014). Recent observations suggest that $M$. atlantica has expanded its geographical distribution, establishing new populations in the Western English Channel (Blackett et al. 2014) and the Mediterranean and Adriatic (Licandro et al.
2012, Batistić et al. 2013), probably in response to hydroclimatic changes. Large blooms of $M$. atlantica have caused dramatic ecological (Greve 1994, Kršinić \& Njire 2001) and economic (Fosså et al. 2003, Baxter et al. 2011) ramifications, particularly in novel habitats. Knowledge of the population dynamics and environmental requirements of this species is needed to fully appreciate its role in coastal marine ecosystems. However, our understanding is hampered by a paucity of data on its different life stages.

The present study is based on observations of the polygastric and eudoxid life stages of $M$. atlantica and the congeneric Muggiaea kochi in the Western English Channel between 2009 and 2013. We investigated seasonal changes in the abundance of these key life-cycle stages to better understand the dynamics that characterise their population development. Identifying the main biological and physical factors that influenced population development allowed us to explore environmental cues that influence their phenology in the Western English Channel.

\section{MATERIALS AND METHODS}

\section{Sampling station}

Data analysed in the present study were collected as a part of ongoing zooplankton research conducted by the Western Channel Observatory (www.western channelobservatory.org.uk). Data were collected weekly at a coastal station, L4 $\left(50^{\circ} 15^{\prime} \mathrm{N}, 4^{\circ} 13^{\prime} \mathrm{W}\right)$ located 7.5 nautical miles $(\sim 13.9 \mathrm{~km})$ southwest of Plymouth, UK, in proximity to the $50-\mathrm{m}$ isobath. Stn L4 is characterised by high seasonal variability. Intense primary productivity occurs during the spring and autumn (Widdicombe et al. 2010), with the summer period characterised by stratified and nutrient-depleted waters (Smyth et al. 2010). Patterns of water circulation are typically characterised by an eastward coastal trajectory, delivering waters of a more northerly or southerly origin, dependent upon the prevailing wind patterns (Pingree \& Griffiths 1980). Strong tidal influence (Pingree 1980) and periodic fluvial input from the Tamar estuary (Smyth et al. 2010) are also dominant hydrographic features.

\section{Physical data}

A SeaBird SBE 19plus Profiler was used to obtain depth profiles of a range of physical and chemical environmental parameters (temperature, salinity, 
water column stratification and dissolved oxygen) (see Smyth et al. 2010 for further methodological details). Temperature $\left({ }^{\circ} \mathrm{C}\right)$ and salinity data were integrated between the surface and $50 \mathrm{~m}$ depth. Water column stratification was assessed in terms of mixed-layer depth (MLD), estimated as the depth at which water density $\left(\mathrm{kg} \mathrm{m}^{-3}\right)$ exceeded a near-surface $(10 \mathrm{~m})$ reference value by a set threshold $\left(0.003 \mathrm{~kg} \mathrm{~m}^{-3}\right.$ ) (de Boyer Montégut et al. 2004). Dissolved oxygen data were not included in the analysis because they were highly correlated with temperature $(r=-0.86)$.

\section{Muggiaea and other zooplankton data}

Zooplankton samples were collected in duplicate by vertical hauls from the sea floor to surface using a WP2 net (mesh size $=200 \mu \mathrm{m}$, mouth area $=0.25 \mathrm{~m}^{-2}$ ) (UNESCO 1968). To reduce inter-sample variability, duplicate samples were averaged and data represented as the number of individuals or colonies per cubic metre (see Eloire et al. [2010] for a detailed description of the sampling methodology).

Siphonophore colonies are fragile and are rarely collected intact by nets. However, the number of Muggiaea atlantica and Muggiaea kochi nectophores provided a direct estimate of their polygastric abundance as species of the genus Muggiaea develop only a single nectophore (Mackie et al. 1987). Enumeration of the Muggiaea spp. eudoxid stage was based upon the number of detached bracts and intact colonies. The eudoxid stages of the genus Muggiaea are morphologically indistinguishable (Kirkpatrick \& Pugh 1984) and were represented by their total abundance.

Specific zooplankton taxa were selected as potential sources of prey using size-range $(100-1000 \mu \mathrm{m})$ (Purcell 1981) and prey-suitability (Purcell 1982, Mapstone 2009) criteria (Table 1).

\section{Numerical analyses \\ Data preparation}

To stabilise variance, biological data were $\log _{10}(x+1)$ transformed. For both physical and biological variables, randomly spaced missing data $(\sim 12 \%$ of the total 260 weekly observations) were interpolated using the eigenvector filtering with missing data method (Ibañez \& Conversi 2002). All analyses were programmed using MATLAB (R2014b 8.4.0.150421).

\section{Eudoxid stage identity}

Since the eudoxid stage is produced directly (asexually) by the polygastric stage (Carré \& Carré 1991), and eudoxid production rates are linearly related to the size of the polygastric colony (Purcell 1982), a tight coupling of their abundance could be expected. Indeed, previous observations have shown that the sexual and asexual stages of both $M$. atlantica and $M$. kochi typically covary in phase (Dowidar 1992). Consequently, the relative contribution of $M$. atlantica and $M$. kochi to the total abundance of Muggiaea spp. eudoxid stages was estimated using simple linear regression. Muggiaea spp. eudoxid stage abundance (response variable) was regressed on $M$. atlantica and then $M$. kochi polygastric abundance (explanatory variables) to quantify the strength of each species association with the total abundance of Muggiaea spp. eudoxid stages. The regression model assumptions of linearity, homogeneity of variance, normality and independence of residuals were carefully monitored. Standard Newey-West heteroscedasticity and autocorrelation consistent covariance estimators (HAC) were used to provide robust estimates of regression parameter variance and facilitate sound statistical inference (Andrews \& Monahan 1992).

Table 1. Percentage relative contribution of different taxa to the total potential prey availability for $M$. atlantica at the sampling location. Taxa were selected following size range and prey suitability criteria derived from the literature (Purcell 1981, 1982, Mapstone 2009)

\begin{tabular}{|c|c|c|c|c|c|c|c|c|}
\hline \multirow[t]{2}{*}{ Season } & \multirow[b]{2}{*}{$\begin{array}{c}\text { Calanoida } \\
\text { (CVI) }\end{array}$} & \multirow[b]{2}{*}{$\begin{array}{c}\text { Calanoida } \\
\text { (CI-CV) }\end{array}$} & \multirow[b]{2}{*}{ Cyclopoida } & \multirow{2}{*}{$\begin{array}{c}\text { Pre } \\
\text { Harpacta- } \\
\text { coida }\end{array}$} & \multirow{2}{*}{$\begin{array}{l}\text { taxa } \\
\text { Poecilo- } \\
\text { stomatoida }\end{array}$} & \multirow[b]{2}{*}{$\begin{array}{c}\text { Copepoda } \\
\text { (napulii) }\end{array}$} & \multirow[b]{2}{*}{ Bivalvia } & \multirow[b]{2}{*}{ Cirripedia } \\
\hline & & & & & & & & \\
\hline Winter & 22.0 & 17.1 & 13.4 & 0.6 & 17.4 & 1.7 & 0.9 & 2.6 \\
\hline Spring & 20.1 & 20.0 & 10.3 & 0.8 & 2.8 & 0.7 & 0.1 & 16.1 \\
\hline Summer & 22.4 & 24.5 & 9.8 & 0.5 & 2.8 & 3.1 & 0.6 & 0.7 \\
\hline Autumn & 25.9 & 20.4 & 3.8 & 1.6 & 14.9 & 1.3 & 1.2 & 0.5 \\
\hline
\end{tabular}




\section{Seasonal variability}

The dominant modes of temporal variability were extracted for the biological and physical variables using the eigenvector filtering (EVF) method (Colebrook 1978, Ibañez \& Etienne 1992). The EVF method involves a principal component analysis performed on an autocovariance matrix composed of the original series lagged progressively; the number of lags (8-11 wk) was defined as the time lag at which the autocorrelation function of the original series first passed zero (Ibañez \& Etienne 1992). The EVF technique decomposes a time series into successive signals of decreasing variance. A cumulative variance threshold of $80 \%$ was used to determine the number of principal components (PC) retained (Ibañez \& Conversi 2002). The main periodicities that characterised the PCs were then estimated using the autocorrelation function (Legendre \& Legendre 2012).

\section{Population dynamics}

The functional relationship between the abundance of eudoxid and polygastric stages was investigated using simple linear regression. Following the procedure described for eudoxid stage identity, regression analyses were computed between the PCs of the polygastric (explanatory variable) and eudoxid (response variable) life-cycle stages and the studentised residuals were retained for analyses. The residuals represent deviations from the typical linear relationship between the abundance of eudoxid and polygastric stages. Positive residuals indicate that increased abundance of the eudoxid stage was observed relative to that which would be expected from the linear eudoxid-polygastric relationship, while negative residuals indicate the inverse. We considered residuals greater than \pm 1 SD as significant deviations from the expected abundance of the eudoxid stage.

\section{Correlations with environmental variables}

Hypothetical links between variability of $M$. atlantica and physical environmental factors (as the PCs) were evaluated using Pearson product moment correlation analyses. Links with biological variables (as the PCs) were explored using partial correlation analyses, allowing the effects of controlling physical variables to be removed. For all correlation analyses, the effective degrees of freedom $\left(\mathrm{df}_{\mathrm{a}}\right)$ were corrected for autocorrelation following the modified Chelton method proposed by Pyper \& Peterman (1998). All data were standardised at zero mean and unit deviation (z-scored) for correlation analyses.

\section{Critical environmental ranges}

For environmental factors that were significantly correlated with the PC2 of $M$. atlantica and residuals of the expected abundance of eudoxids, we identified critical environmental ranges using quotient plot analysis (van der Lingen et al. 2001). Quotient plot analysis quantifies the association of species abundance with categories of environmental parameters, providing an estimate of positive and negative associations.

Quotient values $\left(Q_{i}\right)$ were computed as:

$$
Q_{i}=\frac{M_{i}}{E_{i}}
$$

where $M_{i}$ is the percentage of the total abundance of M. atlantica in environmental category $i$ and $E_{i}$ is the percentage frequency of occurrence of environmental category i. $Q_{i}=1$ indicate a random association of species abundance and related environmental categories, whereas $Q_{i}>1$ indicate a positive association and $Q_{i}<1$ indicate a negative association. The statistical significance of associations was evaluated using a randomisation test with 10000 permutations to compute CI with $\alpha=0.05$. For this analysis the negative and positive residuals were analysed separately. This procedure involved first inverting the negative residuals, then re-scaling both the positive and negative residual between 0 and 1 . This procedure enabled the association of both positive and negative residuals with environmental categories to be assessed. The intervals of environmental categories were chosen by a compromise between the resolution of the profiles and the number of data points within each category. To ensure representation of data within each category, copepod abundance scores in excess of the 95th percentile were omitted from this stage of the analysis ( $<7 \%$ of the 260 observations).

\section{RESULTS}

\section{Eudoxid stage identity}

Inspection of the raw data showed that the abundance of the polygastric stage of $M$. atlantica and the eudoxid stage of Muggiaea spp. fluctuated in 

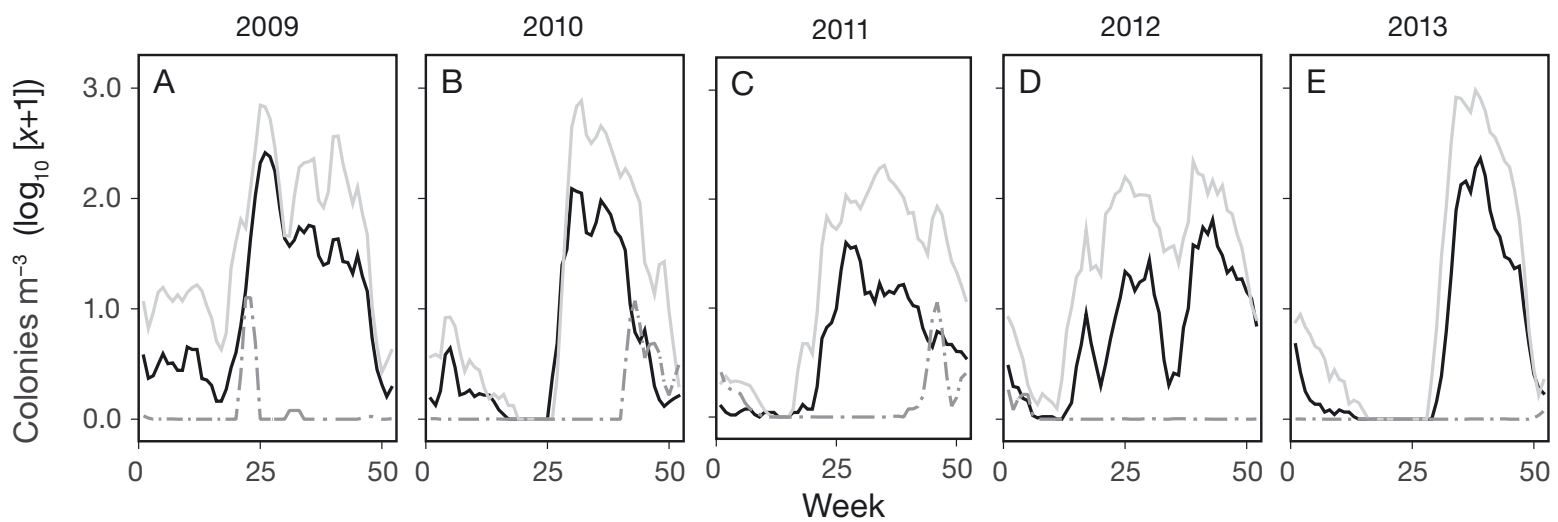

Fig. 1. Temporal fluctuation in the abundances of Muggiaea atlantica polygastric stage (solid black line), Muggiaea kochi polygastric stage (dash-dotted grey line), and Muggiaea spp. eudoxid stage (solid grey line) at Stn L4 in the Western English Channel between 2009 and 2013. Data are weekly abundance values that have been smoothed with a 3-week moving average to improve legibility

phase (Fig. 1). Polygastric M. kochi were less abundant and did not vary in the same way (Fig. 1, Table 2). Linear regression analysis confirmed a significant relationship between the raw abundance (decimal logarithm) of the polygastric stage of $M$. atlantica and the Muggiaea spp. eudoxid stage $(\beta=$ 1.15, $\left.\mathrm{r}^{2}=0.80, F=989, \mathrm{df}=258, \mathrm{p}<0.001\right)$. The number of $M$. kochi polygastric colonies was not associated with eudoxid stage variability ( $\beta=0.27$, $\left.\mathrm{r}^{2}=0.003, F=1.4, \mathrm{df}=258, \mathrm{p}>0.05\right)$ nor the residuals from the $M$. atlantica-eudoxid model ( $\beta=0.33$, $\left.\mathrm{r}^{2}=0.03, F=10.4, \mathrm{df}=258, \mathrm{p}>0.05\right)$. These results provided a clear indication that the eudoxid population was composed primarily of $M$. atlantica. Whilst the possibility of a small contribution from M. kochi cannot be completely eliminated, it was considered negligible. Total eudoxid abundance was considered to represent $M$. atlantica eudoxid abundance and $M$. kochi was not included in further analyses.

Table 2. Mean $\pm \mathrm{SD}$ and 95th percentile abundance (colonies $\mathrm{m}^{-3}$ ) of $\mathrm{Mug}$ giaea spp. at Stn L4 in the Western English Channel between 2009 and 2013

\begin{tabular}{|c|c|c|c|c|c|}
\hline & 2009 & 2010 & 2011 & 2012 & 2013 \\
\hline \multicolumn{6}{|c|}{ Muggiaea atlantica } \\
\hline Mean & $39 \pm 69$ & $25 \pm 60$ & $8 \pm 12$ & $14 \pm 20$ & $32 \pm 76$ \\
\hline 95th percentile & 229 & 123 & 35 & 69 & 222 \\
\hline \multicolumn{6}{|l|}{ Muggiaea kochi } \\
\hline Mean & $3 \pm 16$ & $1 \pm 5$ & $1 \pm 3$ & $0 \pm 0$ & $0 \pm 0$ \\
\hline 95th percentile & 0 & 6 & 7 & 0 & 0 \\
\hline \multicolumn{6}{|c|}{ Muggiaea spp. eudoxid } \\
\hline Mean & $136 \pm 212$ & $128 \pm 305$ & $55 \pm 66$ & $66 \pm 74$ & $165 \pm 344$ \\
\hline 95th percentile & 505 & 567 & 186 & 241 & 1145 \\
\hline
\end{tabular}

\section{Seasonal variability}

Eigenvector filtering (EVF) decomposed the polygastric and eudoxid stage $M$. atlantica time series into 2 principal components: PC1 and PC2 (Fig. 2). PC1 accounted for $58 \%$ and $62 \%$ of the respective total polygastric and eudoxid stage variability, while PC2 explained a further $25 \%$ and $24 \%$. These components represented harmonics of the seasonal cycle, with periodicities of $54 \mathrm{wk}$ (PC1) (Fig. 3A) and $22 \mathrm{wk}$ (PC2) (Fig. 3B). PC1 represented broad-scale changes in the absolute magnitude and distribution of seasonal abundance (Fig. 2A-E), while PC2 represented the underlying fine-scale dynamics that drove this variability (Fig. 2F-J).

Inspection of the broad-scale seasonal variability (PC1) revealed that in 2010 and 2013 polygastric and eudoxid stage $M$. atlantica exhibited restricted periods of abundance that occurred relatively late in the year, during the autumn weeks (Fig. 2B,E). This pattern was in contrast to the other 3 years analysed (2009, 2011 and 2012), during which periods of high abundance occurred earlier (summer) and were more extensive. Compared to the other years analysed, the magnitude of peak abundance of the eudoxid, and particularly the polygastric stage, was comparatively low in 2011 and 2012. The winter minima separating these 2 years was also less extreme (Fig. 2C,D).

Fluctuation at the fine-scale (PC2) revealed the underlying dynamics behind patterns of seasonal variabil- 

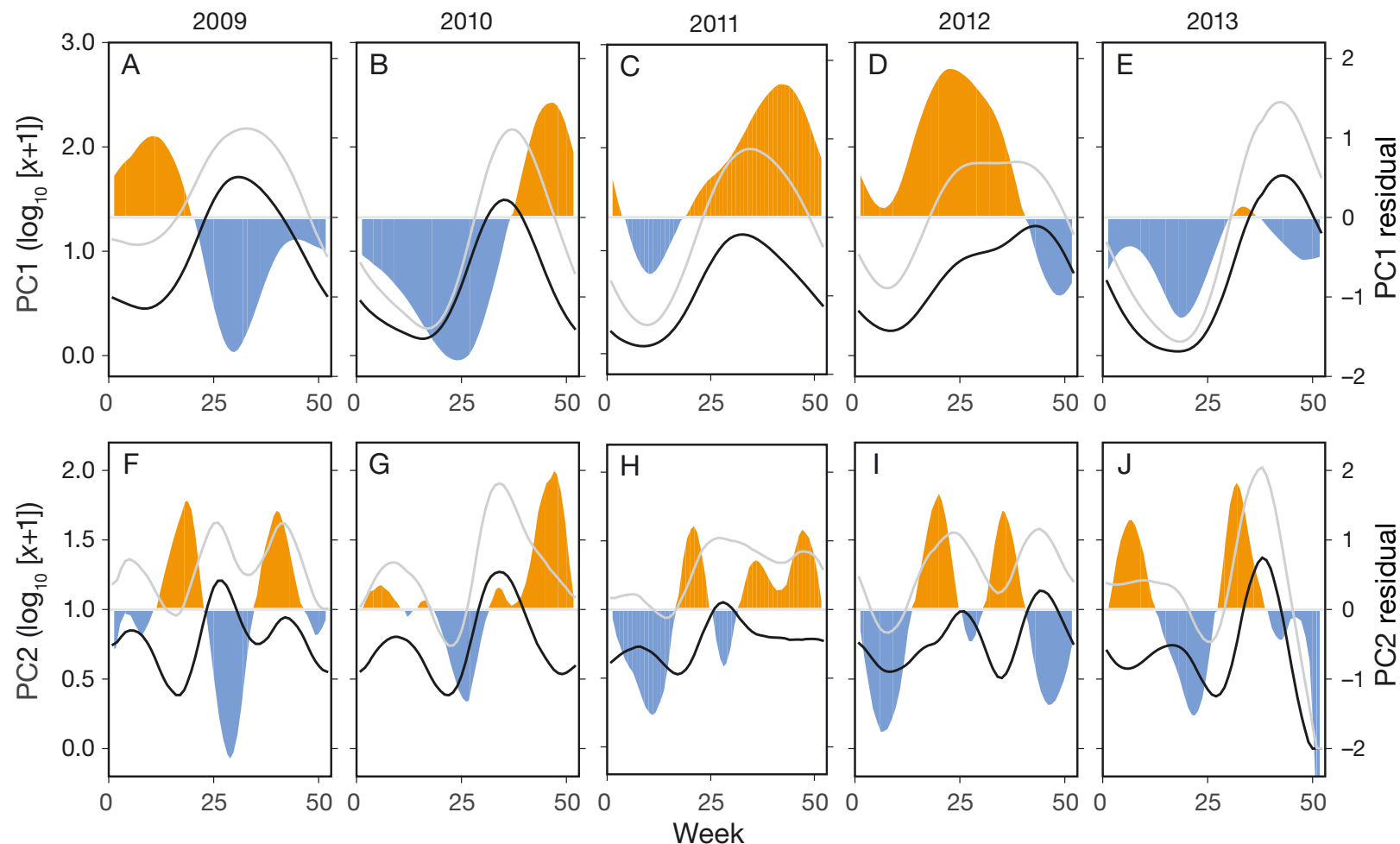

Fig. 2. (A-E) Broad temporal scale (PC1), and (F-J) fine temporal scale (PC2) population dynamics of Muggiaea atlantica between 2009-2013, showing polygastric stage (black lines) and eudoxid stage (grey lines) abundances. Orange and blue shaded areas represent, respectively, positive and negative residuals of the expected eudoxid stage abundance

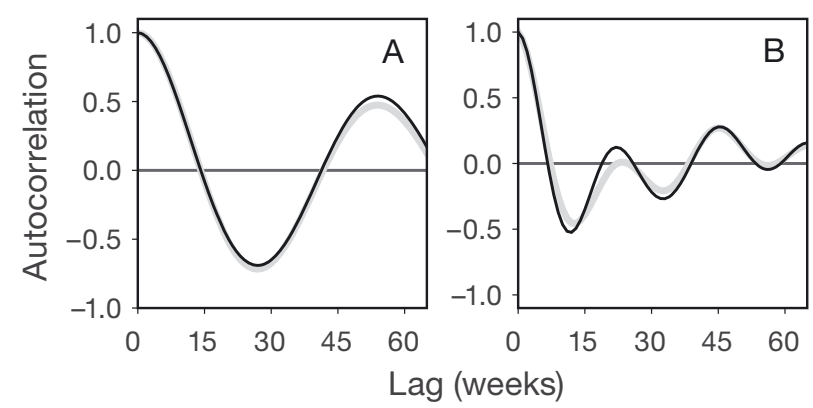

Fig. 3. Periodicity of (A) broad-scale and (B) fine-scale fluctuation in the abundance of Muggiaea atlantica polygastric (black lines), and eudoxid (grey lines) stages derived from the autocorrelation function

ity (Fig. 2F-J). During the years 2010 and 2013, which were characterised by restricted periods of seasonal M. atlantica abundance, single high-amplitude peaks of abundance were observed in September (weeks 34 and 38, respectively). This pattern was in contrast to the other 3 years analysed. In 2009 and 2012, 2 discrete low-amplitude peaks of abundance were evident, the first occurring in week 27 (June) and the second during weeks 42-44 (October). In 2011, a low-amplitude peak of abundance occurred in week 27 (June), after which abundance remained relatively high. Very low amplitude peaks of abundance in the winter were also a common feature, although this peak was less apparent in 2012.

\section{Population dynamics}

Linear regression analyses revealed strong relationships between the PC1 of polygastric and eudoxid stage abundance $\left(\beta=1.23, \mathrm{r}^{2}=0.92, F=2783\right.$, $\mathrm{df}=$ $258, \mathrm{p}<0.001)$. The residuals derived from this regression model oscillated with a periodicity of $44 \mathrm{wk}$ (Fig. 4A) and represented broad-scale changes in the absolute magnitude of eudoxid stage abundance relative to that of the polygastric stage (Fig. 2A-E). In 2011 and 2012, PC1 residuals were consistently positive, indicating that these years were characterised by high relative abundance of eudoxid stage compared to the other years studied (Fig. 2C,D).

The residuals derived from the linear regression of PC2 eudoxid and polygastric stage abundance $(\beta=$ 1.19, $\mathrm{r}^{2}=0.87, F=1127, \mathrm{df}=258, \mathrm{p}=<0.001$ ) fluctuated regularly (Fig. 2F-J) with a periodicity of $26 \mathrm{wk}$ (Fig. 4B). The PC2 residuals represented deviations from the expected abundance of the eudoxid stage associated with cycles of production and decline. 


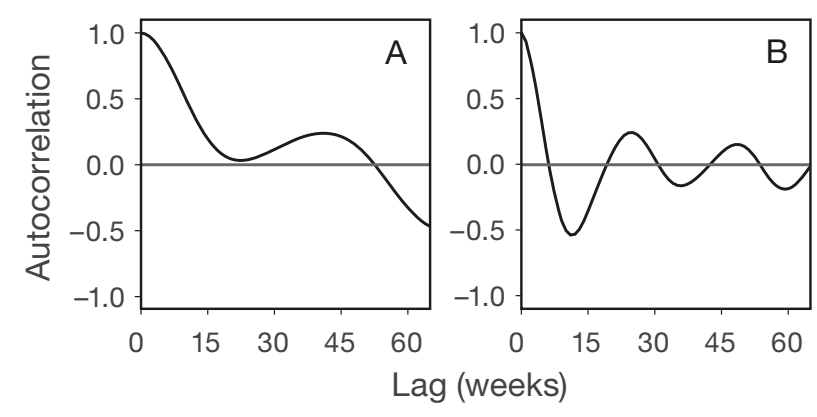

Fig. 4. Periodicity of (A) broad-scale and (B) fine-scale residuals of the expected abundance of the eudoxid stage of Muggiaea atlantica, computed using the autocorrelation function. The residual eudoxid abundance is the studentised residuals derived from the linear regression of the eudoxid and polygastric stages and indicates deviations from the expected abundance of eudoxids based on their typical relationship

High positive residuals were typically observed in the initial phases of population increase (Fig. 2F-J). These spikes of higher than expected eudoxid abundance suggested periods of accelerated eudoxid production. However, in 2010 the period of population increase was characterised by negative residuals, suggesting that during this year the rate of eudoxid production was comparatively low. Otherwise, negative residuals were typically observed following peaks of abundance (Fig. 2F-J), which indicated that the abundance of the eudoxid stage typically declined more rapidly than the polygastric. However, in 2010 the period of population decline was characterised by positive residuals (Fig. 2G), suggesting that during this period the eudoxid stage was more persistent than in the other years. trast, the PC1 abundance of the eudoxid stage decreased considerably during the 2 coldest winters (2010 and 2013). The PC2 residuals were also positively correlated with temperature (Table 3), confirming the importance of temperature to the phenology of $M$. atlantica. Depth-integrated salinity also emerged as a potentially important variable, being correlated positively with PC1 of both eudoxid abundance and the residuals (Fig. 6A-E, Table 3). The analysis showed that certain prey items were potentially important covariates after the effects of temperature were controlled for using partial correlation analysis (Table 4). Positive correlations were found between the PC1 and PC2 residuals and the abundance of calanoid (particularly copepodid stages CI-CV) and cyclopoid copepods (Stage CVI) (Fig. 6F-J, Table 4). The abundance of polygastric and eudoxid stages was positively correlated with the abundance of bivalve larvae at the fine-scale (PC2) (Fig. 5F-J, Table 4).

\section{Critical environmental ranges}

Quotient plot analyses revealed critical thermal ranges associated with the development and phenology of the $M$. atlantica population (as PC2). The analysis did not reveal any associations with specific conditions of salinity or water column stratification. For both the polygastric and eudoxid stages, high PC2 abundance was significantly associated with temperatures above $12.9^{\circ} \mathrm{C}$, while a negative association was found with temperatures below $12.8^{\circ} \mathrm{C}(\mathrm{p}<$ 0.001) (Fig. 7A,B). High positive PC2 residuals, indicating accelerated eudoxid production, were significantly associated initially with a spring increase in

\section{Correlations with environmental variables}

The results of correlation analysis between the principal components of environmental factors and $M$. atlantica variability are presented in Tables 3 \& 4. Both the PC1 and PC2 of M. atlantica polygastric and eudoxid stage abundance were positively correlated with depth-integrated temperature (Fig. 5A-E, Table 3). The less extreme minima observed in the PC1 signals of temperature and $M$. atlantica abundance in 2011 and 2012 indicated increased survivorship during the warmest winter of the 5 years. In con-
Table 3. Pearson product moment correlations for Muggiaea atlantica polygastric, eudoxid, and residuals of eudoxid abundance as a function of physical environmental variables at broad (PC1) and fine (PC2) temporal scales. T: temperature; MLD: mixed layer depth. $\mathrm{df}_{\mathrm{a}}$ : degrees of freedom after correction for autocorrelation. Bold values indicate statistical significance $(p<0.05)$. ns: not significant

\begin{tabular}{|lccccccccccr|}
\hline & \multicolumn{3}{c}{ Polygastric } & \multicolumn{3}{c}{ Eudoxid } & \multicolumn{3}{c|}{ Residual } \\
& $\mathrm{r}$ & $\mathrm{p}$ & $\mathrm{df}_{\mathrm{a}}$ & $\mathrm{r}$ & $\mathrm{p}$ & $\mathrm{df}_{\mathrm{a}}$ & $\mathrm{r}$ & $\mathrm{p}$ & $\mathrm{df}_{\mathrm{a}}$ \\
\hline PC1 & & & & & & & & & \\
$T$ & $\mathbf{0 . 8 7}$ & $\mathbf{0 . 0 1}$ & $\mathbf{7}$ & $\mathbf{0 . 8 8}$ & $\mathbf{0 . 0 1}$ & $\mathbf{7}$ & 0.19 & $\mathrm{~ns}$ & 19 \\
Salinity & 0.12 & $\mathrm{~ns}$ & 53 & $\mathbf{0 . 3 1}$ & $\mathbf{0 . 0 3}$ & $\mathbf{5 1}$ & $\mathbf{0 . 6 7}$ & $\mathbf{0 . 0 1}$ & $\mathbf{1 3}$ \\
MLD & -0.35 & $\mathrm{~ns}$ & 11 & -0.28 & $\mathrm{~ns}$ & 11 & 0.21 & $\mathrm{~ns}$ & 17 \\
& & & & & & & & & \\
PC2 & & & & & & & & & \\
$T$ & $\mathbf{0 . 5 7}$ & $\mathbf{0 . 0 0}$ & $\mathbf{2 3}$ & $\mathbf{0 . 6 8}$ & $\mathbf{0 . 0 0}$ & $\mathbf{2 0}$ & $\mathbf{0 . 4 1}$ & $\mathbf{0 . 0 2}$ & $\mathbf{3 2}$ \\
Salinity & 0.15 & $\mathrm{~ns}$ & 27 & 0.21 & $\mathrm{~ns}$ & 24 & 0.19 & $\mathrm{~ns}$ & 39 \\
MLD & 0.01 & $\mathrm{~ns}$ & 258 & 0.00 & $\mathrm{~ns}$ & 258 & 0.00 & $\mathrm{~ns}$ & 258 \\
& & & & & & & & & & & \\
\hline
\end{tabular}


Table 4. Partial correlation analyses of Muggiaea atlantica polygastric, eudoxid, and residual eudoxid abundance as a function of biological environmental variables at broad (PC1) and fine (PC2) temporal scales. Partial correlation analysis allowed the effect of temperature to be controlled for. $\mathrm{df}_{\mathrm{a}}$ : degrees of freedom after correction for autocorrelation. Bold values indicate statistical significance $(p<0.05)$. ns: not significant

\begin{tabular}{|c|c|c|c|c|c|c|c|c|c|}
\hline & \multicolumn{3}{|c|}{ Polygastric } & \multicolumn{3}{|c|}{ Eudoxid } & \multicolumn{3}{|c|}{ Residual } \\
\hline & $r$ & $\mathrm{p}$ & $\mathrm{df}_{\mathrm{a}}$ & $r$ & $\mathrm{p}$ & $\mathrm{df}_{\mathrm{a}}$ & $r$ & $\mathrm{p}$ & $\mathrm{df}_{\mathrm{a}}$ \\
\hline \multicolumn{10}{|l|}{ PC1 } \\
\hline \multicolumn{10}{|l|}{ Copepoda } \\
\hline Calanoida (CVI) & 0.09 & ns & 33 & 0.17 & ns & 34 & 0.17 & $\mathrm{~ns}$ & 17 \\
\hline Calanoida (CI-CV) & 0.16 & ns & 22 & 0.20 & ns & 22 & 0.27 & 0.03 & 17 \\
\hline Cyclopoida & 0.22 & ns & 26 & 0.32 & ns & 27 & 0.41 & 0.03 & 28 \\
\hline Poecilostomatoida & -0.05 & ns & 10 & 0.02 & ns & 10 & 0.26 & ns & 17 \\
\hline Harpacticoida & -0.28 & ns & 13 & -0.26 & ns & 14 & 0.03 & ns & 23 \\
\hline Nauplii & 0.35 & ns & 13 & 0.32 & ns & 13 & -0.03 & ns & 32 \\
\hline Bivalvia & 0.27 & ns & 11 & 0.28 & ns & 11 & 0.07 & ns & 26 \\
\hline Cirripedia & -0.17 & ns & 17 & -0.17 & ns & 17 & -0.04 & ns & 41 \\
\hline \multicolumn{10}{|l|}{ PC2 } \\
\hline \multicolumn{10}{|l|}{ Copepoda } \\
\hline Calanoida (CVI) & 0.12 & ns & 21 & 0.30 & ns & 23 & 0.44 & 0.05 & 21 \\
\hline Calanoida (CI-CV) & 0.12 & ns & 22 & 0.27 & ns & 24 & 0.51 & 0.02 & 20 \\
\hline Cyclopoida & 0.22 & ns & 36 & 0.24 & ns & 41 & 0.25 & 0.10 & 46 \\
\hline Poecilostomatoida & 0.00 & ns & 23 & 0.04 & ns & 22 & 0.11 & ns & 23 \\
\hline Harpacticoida & -0.11 & ns & 50 & -0.01 & $\mathrm{~ns}$ & 58 & 0.12 & ns & 35 \\
\hline Nauplii & 0.13 & ns & 122 & 0.12 & ns & 136 & 0.02 & ns & 113 \\
\hline Bivalvia & 0.36 & 0.02 & 42 & 0.29 & 0.05 & 47 & -0.13 & ns & 39 \\
\hline Cirripedia & -0.01 & ns & 63 & 0.02 & ns & 77 & 0.10 & ns & 49 \\
\hline
\end{tabular}

temperature to a critical range of $10.1-11.0^{\circ} \mathrm{C}(\mathrm{p}<0.001)$ (Fig. 7C). Subsequent periods of accelerated eudoxid production in autumn were significantly associated with temperatures of $13.8-15.6^{\circ} \mathrm{C}(\mathrm{p}<$ 0.001) (Fig. 7C). Periods of negative PC2 residuals, indicating accelerated eudoxid decline, were significantly associated with a winter decrease in temperature to a critical thermal range of $8.3-9.5^{\circ} \mathrm{C}(\mathrm{p}=$ 0.001) (Fig. 7C).

The analysis also showed a significant association between the residuals of eudoxid abundance (as PC2) and specific ranges of abundance of copepods and copepodids (Calanoida and Cyclopoida) (Fig. 8). Positive residuals (eudoxid production) were significantly associated with the maximum (as the 95th percentile) abundance of copepods (4392-4768 ind. $\mathrm{m}^{-3}$ ), while
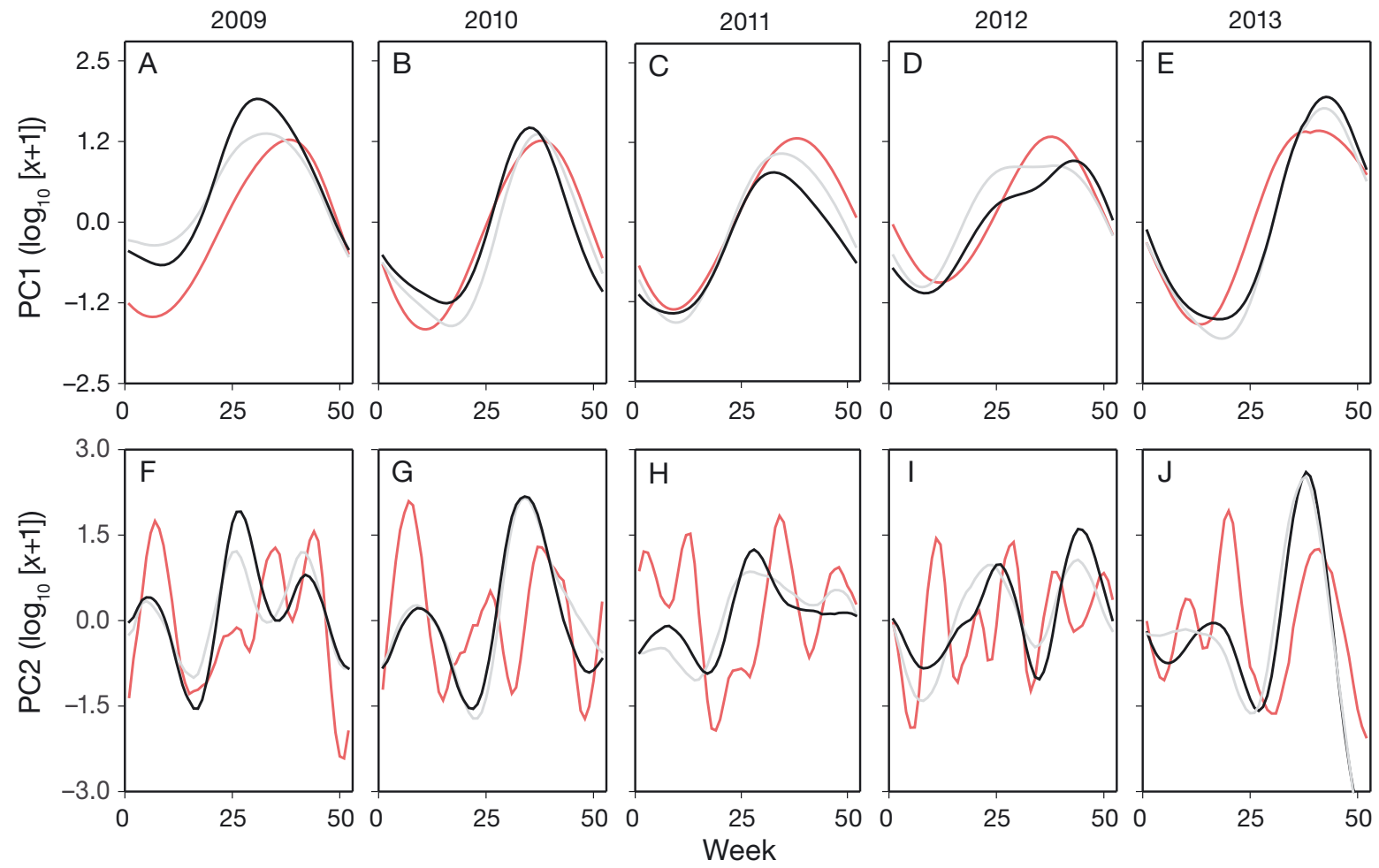

Fig. 5. Synchronous fluctuation of the abundance of Muggiaea atlantica polygastric (black lines) and eudoxid (grey lines) stages and environmental variables (red lines) at different temporal scales. (A-E) Broad-scale variability (PC1) of polygastric and eudoxid abundance with depth-integrated temperature $(r=0.87, p=0.01$, and $r=0.88, p=0.01$, respectively). (F-J) finescale fluctuation (PC2) of polygastric and eudoxid abundance with the PC2 abundance of bivalve larvae $(\mathrm{r}=0.38, \mathrm{p}=0.01$, and $\mathrm{r}=0.31, \mathrm{p}=0.05$, respectively) 

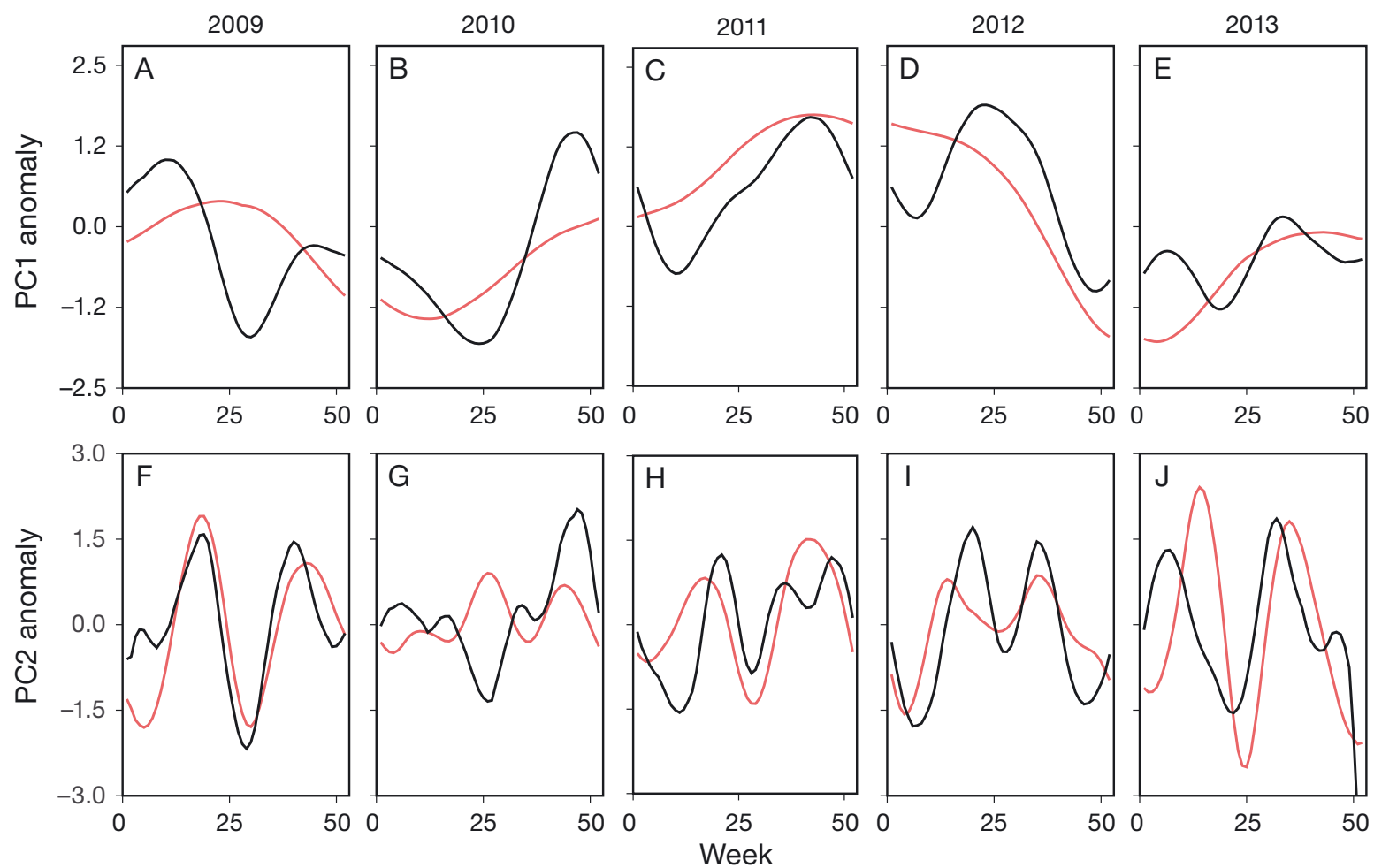

Fig. 6. Synchronous fluctuation of Muggiaea atlantica residual eudoxid abundance (black lines) and environmental variables (red lines) at different temporal scales. (A-E) broad-scale variability (PC1) of residual eudoxid abundance with depthintegrated salinity $(\mathrm{r}=0.67, \mathrm{p}=0.01)$. $(\mathrm{F}-\mathrm{J})$ fine-scale fluctuation $(\mathrm{PC} 2)$ of residual eudoxid abundance with the PC2 abundance of calanoid copepodids $(\mathrm{r}=0.51, \mathrm{p}=0.02)$

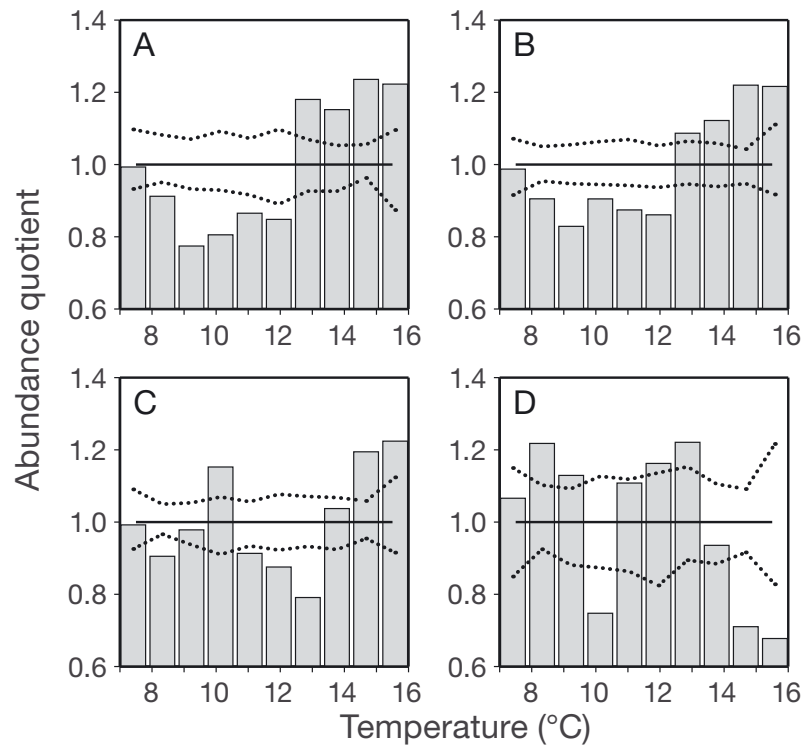

Fig. 7. Thermal preferences of Muggiaea atlantica identified by quotient plot analysis. (A) Polygastric stage abundance, (B) eudoxid stage abundance, (C) positive residuals, indicating accelerated eudoxid production, and (D) negative residuals (inverted), indicating accelerated eudoxid decline. Bars represent abundance quotients within each category of temperature. Solid line denotes quotient value $=1$ (indicating random selection), quotients $>1$ indicate positive association, and quotients $<1$ indicate negative association. Dotted lines denote $95 \%$ CI
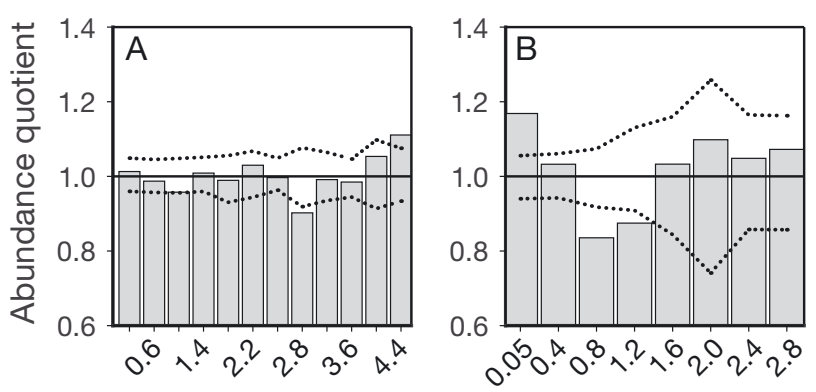

Prey availability $\left(10^{3}\right.$ ind. $\left.\mathrm{m}^{3}\right)$

Fig. 8. Critical ranges of copepod and copepodid (Calanoida and Cyclopoida) prey availability associated with the residual Muggiaea atlantica eudoxid abundance identified by quotient plot analysis. (A) Positive residuals, indicating eudoxid production, and (B) negative residuals, indicating eudoxid decline. Bars represent abundance quotients within each category of temperature. Solid line denotes quotient value 1 (indicating random selection), quotients $>1$ indicate positive association, and quotients $<1$ indicate negative association. Dotted lines denote $95 \%$ CI

negative residuals (eudoxid decline) were significantly associated with the minimum abundance of copepods (53-449 ind. $\mathrm{m}^{-3}$ ).

Our analysis identified a significant influence of temperature and the abundance of copepod prey (particularly calanoid copepodid stages CI-CV) on 

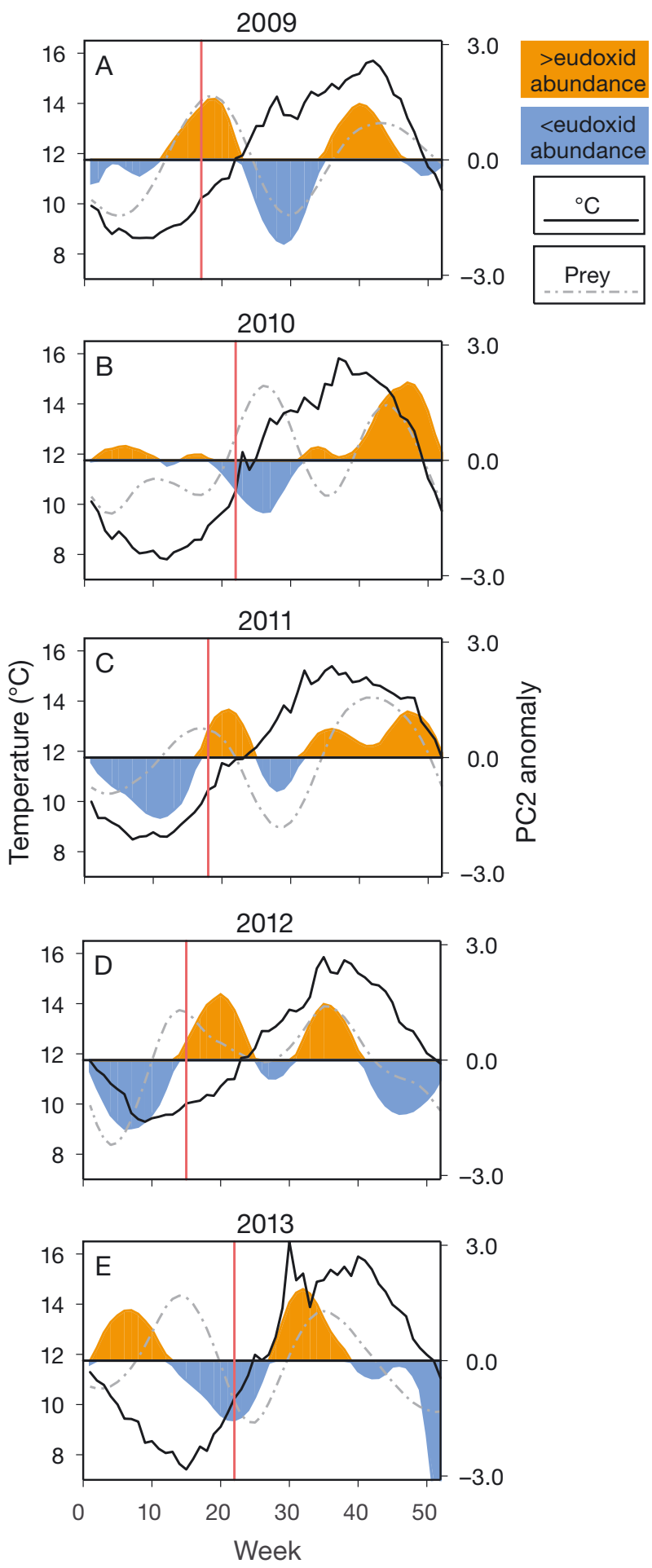

Fig. 9. Representation of the population dynamics of $M$. atlantica in response to interannual variability in temperature (solid black line) and food availability (abundance of calanoid copepodid prey [as the PC2 anomaly]; dash-dotted grey line) in the Western English Channel between 2009 and 2013. Vertical red lines denote the timing of the onset of the critical thermal threshold for eudoxid production. Shaded areas represent positive (orange) and negative (blue) residuals of the expected abundance of the eudoxid stage the residuals of $M$. atlantica eudoxid abundance. Interannual differences in the seasonal dynamics of temperature and prey and how this variability modulated changes in the production and decline of the eudoxid stage is summarised in Fig. 9. During the years 2009, 2011, and 2012 the $M$. atlantica polygastric and eudoxid population exhibited seasonal peaks of abundance in summer and autumn that were preceded by periods of accelerated eudoxid production (Fig. 9A,C,D). These years were characterised by the co-occurrence of maximal copepodid abundance and the onset of a critical thermal threshold for eudoxid production in spring $\left(10^{\circ} \mathrm{C}\right)$. In contrast, the years 2010 and 2013 were characterised by single, comparatively late, seasonal peaks of abundance that occurred in autumn (Fig. 9B,E). During both these years the critical thermal threshold for accelerated eudoxid production was reached in week 22, considerably later than during the other years analysed (weeks 15-18). In 2010 (Fig. 9B), the onset of the critical thermal threshold in late spring was concurrent with moderate copepodid abundance and decelerated eudoxid production. In 2013 (Fig. 9E), the abundance of copepodid prey was at the seasonal minimum when the critical thermal threshold was reached in late spring; under these conditions accelerated eudoxid decline was observed, with accelerated eudoxid production occurring subsequently, concurrent with increased copepodid prey abundance.

\section{DISCUSSION}

Here we modelled the functional relationship between the 2 main life-cycle stages of Muggiaea atlantica, revealing key features of its population dynamics. Our results highlighted a tight coupling between the timing of specific environmental conditions and the development of the $M$. atlantica population, thereby explaining interannual differences in the phenology of its blooms in the Western English Channel.

Both M. atlantica and the congeneric Muggiaea kochi occur in the Western English Channel (Blackett et al. 2014, present study). However, our results only demonstrated a link between the abundance of the polygastric stage of $M$. atlantica and the unidentified Muggiaea spp. eudoxid stage. The congeners M. atlantica and $M$. kochi, have slightly different thermal tolerances and are considered cool-temperate and warm-temperate analogues, respectively (Alvariño 1971). Blackett et al. (2014) have shown that $M$. atlantica is resident in the Western English 
Channel, whereas $M$. kochi is a transient non-resident, probably restricted by low winter temperatures in the Channel. These factors provide strong support for our decision to identify the eudoxids recorded in the present study as $M$. atlantica.

We extracted the dominant modes of temporal variability that characterised the $M$. atlantica population. This procedure allowed us to focus our analysis on seasonal changes in abundance (PC1), and also, the underlying fine-scale dynamics (PC2) that drove this variability. Our results revealed 2 distinct phenological patterns: (1) early spring population development leading to an extended period of abundance with population maxima in both summer and autumn, and (2) late spring population development resulting in a restricted period of abundance with a population maximum in autumn. Phenological variability in calycophoran populations is common at coastal locations in temperate regions (Mackie et al. 1987 and references therein). In some areas this variability appears to be related to localised changes in seasonal hydrographic conditions (Mackie et al. 1987), the effects of which are often difficult to quantify. Indeed, many cnidarian jellyfish populations seemingly appear and disappear irregularly (Graham et al. 2001, Boero et al. 2008). Whilst a multitude of environmental factors undoubtedly contribute, at different levels, to the dynamic of a population (e.g. Hutchinson 1957), our analysis revealed regularity in the phenological response of the $M$. atlantica population to localised variability in temperature and food availability.

Knowledge of the population dynamics of calycophoran siphonophores is sparse. Cyclical changes in the relative abundance of the polygastric and eudoxid stage have been used as an indicator of the life span of generations (Moore 1949, 1952) and as signals of reproductive cycles (Patriti 1964, Mills 1982). In the present study we used the residuals from linear regression analysis to detect when the eudoxid stage was more or less abundant than expected. Considering the fine-scale (PC2) population fluctuation, periods of higher than expected eudoxid abundance were recorded at the onset of $M$. atlantica population growth in spring. Large polygastric colonies typically persist through the winter (Hosia \& Båmstedt 2008) and eudoxid production rates are positively linked to the size of the polygastric colony (Purcell 1982). These factors suggest that periods of higher than expected eudoxid abundance recorded in spring represent the initiation of eudoxid production by the overwintering polygastric population.

The spring pulse of $M$. atlantica eudoxid production recorded in the present study was associated with the occurrence of a specific temperature range $\left(10.0-11.1^{\circ} \mathrm{C}\right)$. Laboratory experiments on the congeneric $M$. kochi in the Mediterranean have shown that polygastric colonies exist in a suspended reproductive state at typical winter temperature, but successfully reproduce at characteristic spring temperature (Carré \& Carré 1991). Since polygastric colonies typically die after asexual reproduction, Carré \& Carré (1991) proposed that reproductive dormancy facilitates overwintering of the polygastric population. Our results support this hypothesis and suggest a critical basal limit of $10^{\circ} \mathrm{C}$ for asexual reproductive activity of $M$. atlantica in the Western English Channel. This thermal limit is in agreement with the results of Blackett et al. (2014) who showed that local development of the $M$. atlantica polygastric population at an open-shelf station in the Western English Channel only occurred when the sea surface temperature was above $9^{\circ} \mathrm{C}$.

In addition to the thermal requirements, siphonophore reproduction is also dependent on food availability (Purcell 1982). Our analysis identified a positive link between deviations from the expected abundance of eudoxids and the abundance of calanoid and cyclopoid copepods. Field studies have shown that copepods and their developmental stages represent the dominant dietary component of $M$. atlantica (Purcell 1981, 1982). Therefore, the availability of copepod prey concurrent with the onset of suitable temperature conditions seems to be an important factor influencing the initiation of asexual reproductive activity in spring. Indeed, high rates of eudoxid production were associated with the maximum abundance of copepod prey, while peak eudoxid decline was associated with the minimum abundance, echoing the experimental results of Purcell (1982). However, copepod availability rapidly declined following the inception of population development, which suggests that other prey taxa must be important during subsequent population growth. We identified a positive relationship between the population density of $M$. atlantica and the abundance of bivalve larvae. Bivalve larvae represent a common prey resource for many other small cnidarian jellyfish (Hansson et al. 2005), and Batistić et al. (2013) reported a similar link with $M$. atlantica in the Adriatic.

The spring pulse of eudoxid production provides the kernel for population development. Sexual reproduction by the eudoxid stage supplies new recruits to the polygastric population that in turn increases the source of eudoxids. During the years 2009, 2011, and 2012, the critical thermal limit for eudoxid production $\left(10^{\circ} \mathrm{C}\right)$ was reached in early spring, coincident with 
the primary maxima of copepod abundance. These conditions provided high food availability leading up to the onset of eudoxid production by the overwintering polygastric stage, likely increasing their reproductive capacity (Purcell 1982). Then as temperature and the abundance of bivalve larvae continued to increase, the high feeding rates and reproductive capacity of M. atlantica (Purcell 1982, Carré \& Carré 1991) allowed rapid population growth that culminated in summer population maxima.

Field studies have indicated an upper thermal limit of $24^{\circ} \mathrm{C}$ for the survival of M. atlantica (Marques et al. 2008, Batistić et al. 2013). Therefore high temperature was unlikely to be a limiting factor in the present study as the maximum average temperature in the Western English Channel is $\sim 16.5^{\circ} \mathrm{C}$ (Smyth et al. 2010). Decline of the M. atlantica population following summer maxima was instead correlated with the reduced availability of larval bivalve prey, suggesting that food limitation was the trigger for population decline. Food limitation is considered a major cause of population decline for many species of cnidarian jellyfish (Pitt et al. 2014 and references therein). Indeed, the effect of food limitation on the abundance of $M$. atlantica eudoxids was pronounced, with the period following the summer maxima being characterised by lower than expected abundance. This decline is probably explained by the combined effect of the cessation of eudoxid production in response to food limitation (Purcell 1982) and the rapid mortality of existing eudoxids that usually have a shorter life span than the polygastric stage (Carré \& Carré 1991). A similar mechanism was responsible for the decline of the M. atlantica population in winter, although the decline was compounded by low winter temperatures. Temperatures $<9.5^{\circ} \mathrm{C}$ represented a limit below which the abundance of eudoxids rapidly declined, potentially signalling the temperature at which the polygastric stage enters reproductive dormancy.

The significance of food availability is further demonstrated by the initiation of secondary population growth during the years characterised by early spring development (2009, 2011, and 2012). Secondary population growth (in autumn) developed in the same way as documented in spring, starting with a pulse of higher than expected eudoxid abundance. This sequence probably represents the initiation of eudoxid production by polygastric colonies remaining from the summer cohort. Given the thermal tolerances of M. atlantica previously documented, a temperature cue for this secondary population development seems unlikely. The pulse of eudoxid produc- tion was coincident with the autumn copepod population maxima, suggesting that relaxation of food limitation could have been the trigger for secondary population development. Subsequent population growth was again correlated with the abundance of bivalve larvae. The similarity between population development in spring and autumn lends weight to our hypothesis that $M$. atlantica population development is in phase with regular cycles of prey and temperature conditions.

The United Kingdom experienced exceptionally cold conditions during the winter of 2009-2010 and the spring of 2013 (www.metoffice.gov.uk/climate/ uk/summaries). These cold conditions extended throughout central and northern Europe (Cattiaux et al. 2010, Andrews 2013) with effects on populations of various aquatic (Edwards et al. 2013) and terrestrial (Glądalski et al. 2014) animals. In the Western English Channel the critical thermal limit for eudoxid production $\left(10^{\circ} \mathrm{C}\right)$ occurred $4-7$ wk later than during the other years. These cold conditions caused a delay to the initiation of M. atlantica population development, which had the effect of disrupting the phasing of eudoxid production with food availability. This trophic mismatch resulted in the development of single autumn population maxima, rather than the summer and autumn peaks recorded during the warmer years.

During 2010 the late onset of M. atlantica population development was characterised by a lower rate of eudoxid production than was identified during the other years analysed. During this year the copepod population displayed an atypical phenology, characterised by a summer, rather than spring, primary maximum. This pattern resulted in an extended period of low copepod prey availability during the winter and spring. Food limitation and low temperatures during this period may have reduced survivorship and limited the growth potential of the overwintering polygastric stages. The reduced eudoxid production at the onset of the critical thermal limit likely reflects the impact of these negative factors on the reproductive capacity of the overwintering polygastric population.

The disruption of phasing between food availability and eudoxid production was more severe in 2013. During this year the critical thermal limit for eudoxid production occurred after the primary (spring) copepod population maxima; instead coinciding with their mid-season minimum. Under these conditions, despite the onset of suitable temperature, eudoxid production was restricted by insufficient food availability. As a result, population development was de- 
layed and only commenced once food availability increased with the autumn copepod peak. The subsequent population maximum occurred in late autumn, 5 weeks later than the time of the 2010 population maximum.

Dramatic seasonal variation of upper-ocean environmental conditions is characteristic of temperate regions (Longhurst 1998). Zooplankton must be able to adapt to variability in the timing and extent of these changes to optimise the phasing of their life cycles with favourable environmental conditions (Mackas et al. 2012). The degree of mismatch between the environmental conditions and the species' environmental requirements influences fitness (Cushing 1990, Durant et al. 2007), with potentially profound effects on the size and phenology of zooplankton populations (Ji et al. 2010, Mackas et al. 2012). Our results highlight the fundamental importance of temperature in shaping cnidarian jellyfish populations. Changes to the seasonal temperature cycle in the Western English Channel produced dramatic shifts in the phenology of the M. atlantica population by modulating the degree of trophic mismatch experienced during the initial phases of population development. Temperature variability has been shown to modify the timing of important developmental events of numerous other species of zooplankton (Beaugrand et al. 2002, Edwards \& Richardson 2004). With direct and indirect effects on virtually all aspects of marine ecosystems (e.g. biological, physical and chemical components), temperature consistently emerges as the most common phenological correlate (Mackas et al. 2012).

Marine organisms with long life spans, such as fish, often employ mechanisms that lead to fixed seasonal timing for reproduction (Cushing 1990). This strategy ensures that, over the long term, reproduction will be in phase with favourable conditions at least during some years, despite interannual variability in the timing of environmental conditions (Cushing 1990, Durant et al. 2007). Because most zooplankton have short $(<1 \mathrm{yr})$ life spans, a fixed seasonal timing window increases the risk that in the event of a 'mismatch', the population will not survive to reproduce in a subsequent year (Mackas et al. 2012). Therefore, zooplankton species tend to reproduce episodically, in response to environmental cues (Mackas et al. 2012). Muggiaea sp. typically have a life cycle in the order of weeks to months (Carré \& Carré 1991). Although we have implied that $M$. atlantica initiates reproduction in response to a fixed thermal threshold $\left(10^{\circ} \mathrm{C}\right)$, we do not consider this temperature as a thermal cue, but rather a physiological limitation. The Western English Chan- nel represents the most northerly recorded habitat supporting a self-sustaining population of $M$. atlantica in the Northeast Atlantic (Blackett et al. 2014 and references therein). At this latitude, $M$. atlantica is likely at the extreme of its thermal tolerance limits. However, the thermal requirements of cnidarian jellyfish are usually location-specific and different populations can adapt to different temperature regimes (Lucas \& Dawson 2014). For instance, the M. atlantica population on the Pacific northwest coast of the United States successfully reproduces at temperatures of $8-10^{\circ} \mathrm{C}$ (Purcell 1982).

The original match-mismatch hypothesis (Cushing 1990) states that a trophic mismatch between predator and prey leads to poor growth, survival and subsequent recruitment. In our study a trophic mismatch with the copepod prey population in the Western English Channel resulted in dramatic phenological shifts of M. atlantica; however the effect on population size was less extreme. Cold spring conditions restricted M. atlantica population development, leading to trophic mismatch and the development of single autumn population maxima with low mean annual abundance. However, the amplitude of these single autumn maxima was higher than peaks during those years where both summer and autumn maxima were recorded. This disparity highlights the resilience and adaptability of $M$. atlantica, and cnidarian jellyfish in general. Their opportunistic life history traits and physiology enable high feeding rates, rapid growth rates, high fecundity and short generation times (Purcell et al. 2007, Acuña et al. 2011). These traits afford cnidarian jellyfish populations great flexibility, enabling rapid conversion of available food energy into large population biomass. The negative impact of a trophic mismatch can be quickly overcome in response to subsequent favourable conditions.

Despite optimal phasing between the onset of eudoxid production and copepod prey availability, during 2011 and 2012 the M. atlantica population density was lower than during the other years analysed. This low abundance was particularly pronounced in the polygastric stage, indicating that the high residual abundance of the eudoxid stage was probably a consequence of reduced polygastric stage production during these 2 years. This result was not linked to a reduction in copepod or bivalve larvae prey availability (data not shown). However, the years 2011 and 2012 were characterised by warmer and more saline conditions than the other years analysed. Although many Calycophora thrive under warm and high salinity conditions (e.g. Buecher 1999), M. atlantica displays euryhaline characteristics and is known 
to tolerate salinities outside the extremes recorded in the present study (Blackett et al. 2014 and references therein). As changes in the salinity conditions could reflect modification to water circulation patterns in the Western English Channel (Pingree 1980), it is possible that advection and migration of $M$. atlantica could explain the low densities recorded in 2011 and 2012.

The seasonal dynamic of the $M$. atlantica population revealed a recurrent low amplitude peak of abundance in winter (weeks 5-10). It is conceivable that this peak could reflect local reproduction during the relatively warm winter conditions of 2013. However, recurrent reproductive activity in winter would appear unlikely given that the winter temperatures typically experienced are below the thermal tolerances of $M$. atlantica discussed above. The $M$. atlantica population in the Western English Channel likely represents the northern component of a spatially extensive Northeast Atlantic metapopulation (Blackett et al. 2014). Pulses of winter abundance observed in the present study could thus indicate immigration from a sub-population located to the south, probably within the Bay of Biscay (reviewed in Mackie et al. 1987). However, the paucity of spatially resolved data within the Channel region limits our understanding of these processes.

In conclusion, this study used in situ observations to establish a theoretical model for $M$. atlantica population dynamics and highlight the significance of the temporal dynamics of temperature and food availability. These findings represent an important addition to our understanding of the ecology of this gelatinous predator, providing preliminary indications of the key temperatures and food ranges that are important for the development and maintenance of its populations in the Northeast Atlantic. However, our ability to interpret and understand observed changes in situ is hampered by our limited knowledge of the species' reproductive biology. Laboratory experiments are required to quantify the reproductive capacity, life spans, and survival of the different life-cycle stages of $M$. atlantica and of other calycophoran siphonophores. Developing an empirical understanding of the ecology of these planktivorous predators can facilitate their incorporation into studies modelling the ecosystems in which they play a fundamental role (e.g. Pauly et al. 2009). Increasing our understanding of the interaction of climate and phenology at the species level and across trophic levels is fundamental to our understanding of the functioning and resilience of marine ecosystems in a changing climate ( $\mathrm{Ji}$ et al. 2010).
Acknowledgements. This work was conducted as part of a PhD Project by M.B. and co-funded by the Natural Environment Research Council and the Sir Alister Hardy Foundation for Ocean Science. We thank Dr. Aino Hosia and 3 anonymous reviewers for their valuable comments and suggestions on the manuscript.

\section{LITERATURE CITED}

Acuña JL, López-Urrutia Á, Colin S (2011) Faking giants: the evolution of high prey clearance rates in jellyfishes. Science 333:1627-1629

Alvariño Á (1971) Siphonophores of the Pacific with a review of the world distribution. Bull Scripps Inst Oceanogr Univ Calif 16:14-32

Andrews DWK, Monahan JC (1992) An improved heteroskedasticity and autocorrelation consistent covariance matrix estimator. Econometrica 60:953-966

Andrews J (2013) How cold Europe was in March 2013. www. accuweather.com/en/weather-blogs/andrews/how-coldeurope-was-in-march-2013/9313909 (Accessed on 15 January 2015)

Batistić M, Lučić D, Carić M, Garić R, Licandro P, Jasprica N (2013) Did the alien calycophoran Muggiaea atlantica outcompete its native congeneric $M$. kochi in the marine lakes of Mljet Island (Croatia)? Mar Ecol 34:3-13

Baxter EJ, Rodger HD, McAllen R, Doyle TK (2011) Gill disorders in marine-farmed salmon: investigating the role of hydrozoan jellyfish. Aquacult Environ Interact 1:245-257

Beaugrand G, Reid PC, Ibañez F, Lindley JA, Edwards M (2002) Reorganization of North Atlantic marine copepod biodiversity and climate. Science 296:1692-1694

Blackett M, Licandro P, Coombs SH, Lucas CH (2014) Longterm variability of the siphonophores Muggiaea atlantica and M. kochi in the Western English Channel. Prog Oceanogr 128:1-14

> Boero F, Bouillon J, Gravili C, Miglietta MP, Parsons T, Piraino S (2008) Gelatinous plankton: Irregularities rule the world (sometimes). Mar Ecol Prog Ser 356:299-310

- Buecher E (1999) Appearance of Chelophyes appendiculata and Abylopsis tetragona (Cnidaria, Siphonophora) in the Bay of Villefranche, northwestern Mediterranean. J Sea Res 41:295-307

> Carré C, Carré D (1991) A complete life cycle of the calycophoran siphonophore Muggiaea kochi (Will) in the laboratory, under different temperature conditions: ecological implications. Philos Trans R Soc Lond B Biol Sci 334:27-32

Cattiaux J, Vautard R, Cassou C, Yiou P, Masson-Delmotte V, Codron F (2010) Winter 2010 in Europe: a cold extreme in a warming climate. Geophys Res Lett 37 : L20704, doi:10.1029/2010GL044613

Colebrook JM (1978) Continuous plankton records-zooplankton and environment, northeast Atlantic and North-Sea, 1948-1975. Oceanol Acta 1:9-23

Condon RH, Duarte CM, Pitt KA, Robinson KL, and others (2013) Recurrent jellyfish blooms are a consequence of global oscillations. Proc Natl Acad Sci USA 110: 1000-1005

> Cushing DH (1990) Plankton production and year-class strength in fish populations: an update of the match/mismatch hypothesis. Adv Mar Biol 26:249-293

de Boyer Montégut C, Madec G, Fischer AS, Lazar A, Iudicone D (2004) Mixed layer depth over the global ocean: 
An examination of profile data and a profile-based climatology. J Geophys Res C Oceans 109:1-20

Dowidar MM (1992). Biométrie et croissance des siphonophores et méduses de la Rade de Villefranche-sur-Me et étude au laboratoire de deux espèces de méduses. $\mathrm{PhD}$ thesis, Pierre et Marie Curie University, Paris

Durant JM, Hjermann D, Ottersen G, Stenseth NC (2007) Climate and the match or mismatch between predator requirements and resource availability. Clim Res 33: 271-283

Edwards M, Richardson AJ (2004) Impact of climate change on marine pelagic phenology and trophic mismatch. Nature 430:881-884

Edwards M, Bresnan E, Cook K, Heath M, and others (2013) Impacts of climate change on plankton. MCCIP Science Review 2013: p 98-112

Eloire D, Somerfield PJ, Conway DVP, Halsband-Lenk C, Harris R, Bonnet D (2010) Temporal variability and community composition of zooplankton at station L4 in the Western Channel: 20 years of sampling. J Plankton Res 32:657-679

Fosså JH, Flood PR, Olsen ABJF (2003) Små og usynlige, men plagsomme maneter av arten Muggiaea atlantica. Fisken Havet 2:99-103 (in Norwegian)

> Glądalski M, Bańbura M, Kaliński A, Markowski M, and others (2014) Extreme weather event in spring 2013 delayed breeding time of Great Tit and Blue Tit. Int J Biometeorol 58:2169-2173

Graham WM, Pagès F, Hamner WM (2001) A physical context for gelatinous zooplankton aggregations: a review. Hydrobiologia 451:199-212

Greve W (1994) The 1989 German bight invasion of Muggiaea atlantica. ICES J Mar Sci 51:355-358

Hansson LJ, Moeslund O, Kiørboe T, Riisgård HU (2005) Clearance rates of jellyfish and their potential predation impact on zooplankton and fish larvae in a neritic ecosystem (Limfjorden, Denmark). Mar Ecol Prog Ser 304: $117-131$

Hosia A, Båmstedt U (2008) Seasonal abundance and vertical distribution of siphonophores in western Norwegian fjords. J Plankton Res 30:951-962

Hutchinson G (1957) A treatise on limnology. Vol 1: Geography, physics, and chemistry. John Wiley \& Sons, London

Ibañez F, Conversi A (2002) Prediction of missing values and detection of 'exceptional events' in a chronological planktonic series: a single algorithm. Ecol Modell 154:9-23

Ibañez F, Etienne M (1992) Le filtrage des séries chronologiques par l'analyse en composantes principales de processus (ACPP). J Res Oceanogr 16:27-33 (in French)

Ji R, Edwards M, MacKas DL, Runge JA, Thomas AC (2010) Marine plankton phenology and life history in a changing climate: Current research and future directions. J Plankton Res 32:1355-1368

Kirkpatrick PA, Pugh PR (1984) Siphonophores and velellids: keys and notes for the identification of the species. In: Kermack DM, Barnes RSK (eds) Synopses of the British Fauna, Vol 29. Linnaean Society of London, Bath

Kršinić F, Njire J (2001) An invasion by Muggiaea atlantica Cunningham 1892 in the northern Adriatic Sea in the summer of 1997 and the fate of small copepods. Acta Adriat 41:49-56

Legendre P, Legendre LFJ (2012) Numerical ecology. Elsevier, Amsterdam

> Licandro P, Souissi S, Ibanez F, Carré C (2012) Long-term variability and environmental preferences of calyco- phoran siphonophores in the Bay of Villefranche (northwestern Mediterranean). Prog Oceanogr 97-100:152-163

Longhurst A (1998) Ecological geography of the sea. Academic Press, London

> Lucas CH (2001) Reproduction and life history strategies of the common jellyfish, Aurelia aurita, in relation to its ambient environment. Hydrobiologia 451:229-246

Lucas CH, Dawson MN (2014) What are jellyfishes and thaliaceans and why do they bloom? In: Pitt KA, Lucas $\mathrm{CH}$ (eds) Jellyfish blooms. Springer, Dordrecht, p 9-44

Mackas DL, Greve W, Edwards M, Chiba S, and others (2012) Changing zooplankton seasonality in a changing ocean: Comparing time series of zooplankton phenology. Prog Oceanogr 97-100:31-62

Mackie GO, Boag DA (1963) Fishing, feeding and digestion in siphonophores. Pubbl staz zool Napoli 33:178-196

> Mackie GO, Pugh PR, Purcell JE (1987) Siphonophore biology. Adv Mar Biol 24:97-262

Mapstone GM (2009) Siphonophora (Cnidaria: Hydrozoa) of Canadian Pacific waters. NRC Research Press

Mapstone GM (2014) Global diversity and review of Siphonophorae (Cnidaria: Hydrozoa). PLoS ONE 9:e87737

> Marques SC, Azeiteiro UM, Leandro SM, Queiroga H and others (2008) Predicting zooplankton response to environmental changes in a temperate estuarine ecosystem. Mar Biol 155:531-541

Matsakis S, Conover RJ (1991) Abundance and feeding of medusae and their potential impact as predators on other zooplankton in Bedford Basin (Nova Scotia, Canada) during spring. Can J Fish Aquat Sci 48:1419-1430

Mills CE (1982) Patterns and mechanisms of vertical distribution of medusae and ctenophores. PhD dissertation, University of Victoria, British Columbia

Mills CE (1995) Medusae, siphonophores, and ctenophores as planktivorous predators in changing global ecosystems. ICES J Mar Sci 52:575-581

Moore HB (1949) The zooplankton of the upper waters of the Bermuda area of the North Atlantic. Bull Bingham Oceanogr Collect 12:1-97

Moore HB (1952) Plankton of the Florida current. II. Siphonophora. Bull Mar Sci 2:559-573

Patriti G (1964) Les siphonophores du Golfe de Marseille. Recl Trav Stn Mar d'Endoume Fac Sci Mars 35:185-258

Pauly D, Graham W, Libralato S, Morissette L, Palomares MLD (2009) Jellyfish in ecosystems, online databases, and ecosystem models. Hydrobiologia 616:67-85

Pingree RD (1980) Physical oceanography of the Celtic Sea and English Channel. Elsevier Oceanogr Ser 24:415-465

Pingree RD, Griffiths DK (1980) Currents driven by a steady uniform wind stress on the shelf seas around the British Isles. Oceanol Acta 3:227-232

Pitt KA, Welsh DT, Condon RH (2009) Influence of jellyfish blooms on carbon, nitrogen and phosphorus cycling and plankton production. Hydrobiologia 616:133-149

Pitt KA, Budarf AC, Browne JG, Condon RH (2014) Bloom and bust: Why do blooms of jellyfish collapse? In: Pitt KA, Lucas $\mathrm{CH}$ (eds) Jellyfish blooms. Springer, Dordrecht, p 79-103

> Purcell JE (1981) Dietary composition and diel feeding patterns of epipelagic siphonophores. Mar Biol 65:83-90

$>$ Purcell JE (1982) Feeding and growth of the siphonophore Muggiaea atlantica (Cunningham 1893). J Exp Mar Biol Ecol 62:39-54

Purcell JE, Uye SI, Lo WT (2007) Anthropogenic causes of jellyfish blooms and their direct consequences for 
humans: a review. Mar Ecol Prog Ser 350:153-174

Pyper BJ, Peterman RM (1998) Comparison of methods to account for autocorrelation in correlation analyses of fish data. Can J Fish Aquat Sci 55:2127-2140

Smyth TJ, Fishwick JR, Lisa AM, Cummings DG and others (2010) A broad spatio-temporal view of the Western English Channel observatory. J Plankton Res 32:585-601

UNESCO (1968) Zooplankion sampling. Monographs on oceanographic methodology. UNESCO, Paris

van der Lingen CD, Hitchings L, Merkle D, van der Westhuizen JJ, Nelson J (2001) Comparative spawning habi-

Editorial responsibility: Marsh Youngbluth,

Fort Pierce, Florida, USA tats of Anchovy (Engraulis capensis) and Sardine (Sardinops sagax) in the Southern Benguela upwelling ecosystem. In: Kruse GH, Bez N, Booth A, Dorn MW and others (eds) Spatial processes and management of marine populations. Univ. Alaska Sea Grant College Program. Rep. No. AK-SG-01-02, p 185-209

> Widdicombe CE, Eloire D, Harbour D, Harris RP, Somerfield PJ (2010) Long-term phytoplankton community dynamics in the Western English Channel. J Plankton Res 32: 643-655

Submitted: January 28, 2015; Accepted: July 13, 2015

Proofs received from author(s): August 24, 2015 